\title{
THE DEVELOPMENT OF RESEARCH RECOMMENDATION SYSTEM FOR SOUTHERN THAILAND DEVELOPMENT
}

\author{
Nawapon Kewsuwun ${ }^{1}$, Kanyarat Kwiecien ${ }^{1}$ and Chumchit Sae-Chan ${ }^{2}$ \\ ${ }^{1}$ Department of Information Science, Faculty of Humanities and Social Sciences, \\ Khon Kaen University, Khon Kaen, Thailand. \\ ${ }^{2}$ Department of Library and Information Science, Faculty of Humanities and \\ Social Sciences, Prince of Songkla University, Pattani, Thailand.
}

\begin{abstract}
The research was to identify needs on design and development of a research recommendation system for 14 southern province Thailand development. The system employs semantic search function, research system structure and scope of knowledge during January 2008 to December 2017. 3,873 entries had been gathered from Thai Library Integrated System (ThaiLIS), Thai National Research Repository (TNRR), and Southern universities research database by employing textual analysis and knowledge organization focusing on Classification Approach and categorization which main topics are sorted and categorized. To develop ontology, it applies knowledge engineering concept and using Protégé Ontology Editor version 3.5 beta and version 5.5 beta to process the data for the accurate system development according to user-centered design concept. The study findings were the developed system is able to support information exchange, information retrieval, and research search and to decrease research redundancy and unnecessary budgeting. Moreover, the system could possible enhance conducting more innovations, confirming experts in the area, showing research trends, and showing research results on related fields, strategies, and problems which leads to the Southern developments extensively. After the implementation, the users' overall opinions and satisfaction was at a high level $(\overline{\mathrm{X}}=4.14, S . D=0.14)$ and information retrieval efficiency of system was at a good level (overall $=0.70-0.88$ ) with 0.70 accuracy, 0.78 recall, 0.88 precision, and 0.82 F-measure.
\end{abstract}

\section{KEYWORDS}

Research recommendation system, southern Thailand development, research for development, information and knowledge management, Ontology.

\section{INTRODUCTION}

South of Thailand is coastal areas along Thai Gulf and Andaman Sea also it is closed to Malaysia border. Therefore, there are advantages on border trade and tourism [1]. Most of the South are forests and wetlands which is valuable for planting and eco-tourism [2]. Besides, the Southern economic structure consists of agriculture, industry, trade, and tourism, moreover, Southern culture portrays its own identity as unique-ness and diversity which could be conveyed as multiculturalism. In accordance to multiculturalism, the South welcomes all tourists as a hub of diversity [3]. These factors are strengths of the South also relate to Thailand 4.0 concept in which the government encourages the people to have outstanding innovations along with creative culture, and to create services which lead to effective product development and tourism services [4]. 
International Journal of Managing Information Technology (IJMIT) Vol. 11, No. 4, November 2019

Southern development policy and strategic plan and the Office of Strategy Management, Southern province group focuses on setting up Thailand stability and sustainable development framework under the sufficient economy concept. Moreover, international network has been brought to help on agriculture, food processing industry, and tourism development which based on economic expansions as increasing various types of business and employment rate also enhancing competitive man-power as to be ready for industry investment and marine transportation development like Joint Development Strategic for Border Area or JDS and Indonesia - Malaysia -Thailand Growth Triangle or IMT - GT [4].

Process on employing strategies into practice and driving the region is based on participation among the people, organizations, and departments in province group for the utmost development [5]. This drive and development pay attention to fundamentals, in other words, the developments on basic structures of economy, society, and community along with research and development on inventing innovations, gaining new knowledge, and solving problems systematically. In terms of development process and problem-solving, it employs needs and problem analysis as to gain findings which lead to practical research methodology [6]. Further research has been used as tools to reach body of knowledge, answers, explanations and systematic development, to reconfirm whether the knowledge is existing, and to see if the knowledge can be applied or solved problems [1]

Conducting research leads to freshly effective innovations which used for further development and precise solutions to strengthen the region and the nation. To con-duct research for development in the South becomes an essential tool in constructing new knowledge which could lead to innovations especially agriculture and fisheries also research on multiculturalism. These 2 research topics included 5 targets which are encouraged and launched by the government [7]. Research procedure includes research problem, research statement, literature review, research framework, population and target group, research design, research tools, data analysis, research findings, and implement [8]. Each step needs information to be part of literature review and to support the ongoing research [9]. Gathering related information expands the area of knowledge to be multidisciplinary, yet due to information overload, it causes unreliability and unclear scope of knowledge.

To ease data search, confirmation, and support research in the South there should be a systematic knowledge management as categorizing and classifying data [10] which is easy to access. The knowledge has been categorized into tree structure according to the relationship of each concept [11] in accordance to policies, plans, strategies, problems context and academic branches. These relationships are combined into the structure of information systems that the semantic web technology uses to search or recommendation system can understand, therefore, it helps on showing clear causes and effects also differentiating relationship in scope of related knowledge in the form of ontology [12] will serve to support the separation relationship process of knowledge scope relevant and not related to each other. Moreover, it helps users making decisions, gathering information, or continuing further research for development in the South. Previous studies regarding recommendation system in Thailand show that there were systems developed for particular topics or areas, for example, a recommendation system for North Eastern Thailand, a system on collecting autobiography, a knowledge database on enhancing services for diabetic patient or a research database on rice. Yet the researchers did not find any research recommendation system for Southern part of Thailand even it is one of the main resources on economic and education in Thailand [1]. Consequently, 14 provinces of the South could not confirm or manage existing knowledge effectively [3]. Besides, the knowledge was scattered; it might need to be managed and shared systematically. 
International Journal of Managing Information Technology (IJMIT) Vol. 11, No. 4, November 2019

Therefore, this research aims to identify needs on design and development of a research recommendation system for 14 southern province Thailand development. The findings in this research will show the relationships and trends of knowledge based on research of Southern Thailand from the synthesized fixed data, additionally, it is beneficial to reflect gaps on some research points which can be resolved or reused. Identifying research knowledge relationships is to point out relationships between research and strategies, policies and needs which relate to problems. To resolve problems effectively a systematically research should be conducted according to existing research knowledge and grant. Further, this could explain more on relationships of information clearly, similarly, the system will help researchers scoping area of study, searching for information, reducing research redundancy, reducing costs on research redundancy and reconfirming existing knowledge, and creating innovations.

\section{RESEARCH OBJECTIVE}

To identify needs on design and development of a research recommendation system for 14 southern province Thailand development.

\section{MAterials AND Methodology}

The search system development focuses on research and development methodology for innovation, new technology, and new knowledge [13] employing research-based development to be a framework for systematic research process as three steps as follows

\subsection{To scope and categorize knowledge found on research for Southern development (Phase 1)}

\subsubsection{Underlying concepts.}

Textual analysis and knowledge organization focusing on Classification Approach have been applied to sort main topics into tree structure. Approach and theoretical framework applied to this system development are based on classification theory or semantic relationship. To categorize knowledge is to sort and group similar content according to subclasses, meanings, purposes, durations, or locations for gathering proper amount of knowledge structure elements on developing the system $[14,15,16,17]$.

\subsubsection{Methodology}

To scope the knowledge 6 references had been used as follows

(1.) 12 disciplines from National Research Council of Thailand (NRCT) which brought to be a criterion on granting research scholarships (2.) 7 strategies from the Ninth National Research Policy and Strategy (2017-2021) formulated by the National Research Council of Thailand (3.) 10 strategies from the Twelfth National Economic and Social Development Plan (2017-2021) and the 20-year National Strategy framework (2017-2036) formulated by the office of the National Economic and Social Development Board (4.) 11 strategies from 3 departments of administration and strategy planning of Southern province group development framework (2018-2021) (5.) Synthesis on problems and needs of people in the Southern province group by the Office of Strategy Management [27, 28] and (6.) Related research on Thai National Research Repository (TNRR), Thai Library Integrated System (ThaiLIS) and southern universities research database in the past 10 years from 2008- 2018 then synthesizing the data according to 3 aspects of research knowledge structure: research documents, research basic information, and other related research 
International Journal of Managing Information Technology (IJMIT) Vol. 11, No. 4, November 2019 information. Those research were carefully selected in terms of correctness, completeness, and conciseness, as a result, there were 3,873 entries from 78 organizations.

(2.) Textual analysis and knowledge organization had been used to develop the system also focused on classification approach to categorize by analyzing contents to get concepts, relationships, and semantic groups of research data [18, 19, 20]. After analyzing the structure was developed based on the 12 disciplines from National Research Council of Thailand, the Ninth National Research Policy and Strategy (2017-2021), the Twelfth National Economic and Social Development Plan (2017-2021) and the 20-year National Strategy framework (2017- 2036), strategies from 3 departments of administration and strategy planning of Southern province group development framework (2018-2021) [27, 28] and the synthesis on problems and needs of people in Southern province group by the Office of Strategy Management. The structure had been evaluated by 28 experts using Index of item Objective Congruence or IOC. Lastly, the system had been fixed according to the experts' feedback and suggestions.

\subsubsection{Result}

Scopes of knowledge on Southern development research are as follows; (1.) Knowledge Structure consists of 2 domains, 32 classes, 226 concepts and 680 sub-concepts; (2.) Domains consists of research aspects domain and research work do-main; (3.) Research aspects domain consists of 29 classes, 200 concepts and 568 sub-concepts; and (4.) Research knowledge sets consists of 3 classes of 1) research documents 2) primary data 3) related data which consists of 26 concepts and 112 sub-concepts [21].

\subsection{Information needs of researchers' on Southern development research (Phase 2)}

\subsubsection{Underlying concepts.}

2 concepts had been adopted to explore researchers' needs as follows;

(1.) Quantitative research and user-centered design had been brought to study the needs focusing on importance, needs, and satisfaction of users. The findings of this assessment are used in the system development process [22]. Moreover, the development uses system approach to construct an effective recommendation system in accordance with the needs and the Southern development strategies. The needs were from 327 researchers of 78 organizations who conducted research regarding Southern Thailand during January 2008 to December 2017. Those 10-year entries had been gathered from Thai Library Integrated System (ThaiLIS), Thai National Research Repository (TNRR), and Southern universities research database which the researchers were able to access. The researchers employed rule of three to get 327 researchers of 78 organizations from the population. After that the researchers used simple random sample method as to get numbers of researchers from each organizations, then collected data from databased. The researchers were able to utilize needs of basic research data, related research data, and suggestions and recommendations on the next phase.

(2.) Qualitative research had been employed as using focus group technique to interview 3 administrators from administration and strategy planning of Southern province group. The administrators were purposively selected regarding responsibilities and job titles in order to gain management concepts and the findings allows the researchers to learn about reconstructing knowledge, research trends, problems and needs of community, needs on having a recommendation system for the Southern part of Thailand which would support and confirm important data for further research and developments. 


\subsubsection{Methodology}

(1.) Related data had been collected by reviewing literature focusing on online research database, research search, and research retrievals to compare and contrast the information for reinventing a needs assessment form. Consequently, the form was a 5-rating scale which divided into 3 parts; 7 items on background information, 40 items on needs in design and system development, and open-ended question on needs, opinions, and suggestions. The needs assessment had been sent by post and personally delivered to 327 researchers from 78 organizations to assess.

(2.) The quantitative data had been collected from June- August 2018 and analyzed quantitatively in terms of frequency, percentage, average, and standard deviation to set system development criteria according to the needs.

(3.) The qualitative data had been collected in a form of interviewing 3 administrators from administration and strategy planning of Southern province group in order to synthesize management concepts of the group. Further, the research proposal and the interview process was confidential and approved by the Center for Ethics in Human Research, Khon Kaen University following the Declaration of Helsinki and ICH GCP

\subsubsection{Findings}

According to the findings on Table 1 - Table 3, the researchers stated the criteria regarding information needs as follows [23].
4.51-5.00 is Very high
2.51-3.50 is Average
3.51-4.50 is High
$1.00-1.50$ is Very low
$1.51-2.50$ is Low

(1.) Synthesized result of researchers' needs on research for Southern development, summarized in Table 1 to Table 3, collected the data from the needs assessment form (quantitative).

Table 1. Average, SD, and overall level of researchers' needs on research for Southern development.

\begin{tabular}{cccc}
\hline \multirow{2}{*}{ Needs items } & \multicolumn{3}{c}{ Level of needs) $\mathbf{n}=\mathbf{3 2 7}($} \\
\cline { 2 - 4 } & $\overline{\mathrm{X}}$ & $\mathbf{S . D}$ & Level \\
\hline 1. Basic research information & 4.07 & 0.66 & High \\
\hline 2. Related research information & 4.15 & 0.61 & High \\
\hline Average & $\mathbf{4 . 1 1}$ & $\mathbf{0 . 6 3}$ & High \\
\hline
\end{tabular}

According to the data in Table 1, the results were the overall of information needs on the system design and development was at a high level as $(\overline{\mathrm{X}}=4.11$, S.D $=0.63)$, additionally, each needs item portrays the same result as it is at the high level. The first two highest needs item were related research information $(\bar{X}=4.15$, S.D $=0.61)$ and basic research information $(\bar{X}=4.07$, S.D $=0.66$ ) respectively. 
International Journal of Managing Information Technology (IJMIT) Vol. 11, No. 4, November 2019

Table 2. Average, SD, and level of researchers' needs on research for Southern development: basic research information aspect

\begin{tabular}{|c|c|c|c|}
\hline \multirow{2}{*}{ Needs items } & \multicolumn{3}{|c|}{ Level of needs $(n=327)$} \\
\hline & $\overline{\mathrm{X}}$ & S.D & Level \\
\hline 1. A subject search function & 4.25 & 0.70 & High \\
\hline 2. A researcher's name search function & 4.25 & 0.73 & High \\
\hline 3. A search function showing researcher's gender & 3.96 & 0.56 & High \\
\hline 4. A search function showing researcher's academic title & 3.92 & 0.70 & High \\
\hline $\begin{array}{l}\text { 5. A search function showing researcher's education } \\
\text { background }\end{array}$ & 3.85 & 0.65 & High \\
\hline 6. A search function on scoping research duration & 3.97 & 0.88 & High \\
\hline 7. A search function showing researcher's active status & 3.94 & 0.66 & High \\
\hline 8. A search function showing research objectives & 4.28 & 0.67 & High \\
\hline
\end{tabular}

Table 2. Average, SD, and level of researchers' needs on research for Southern development: basic research information aspect (cont.)

\begin{tabular}{|c|c|c|c|}
\hline \multirow{2}{*}{ Needs items } & \multicolumn{3}{|c|}{ Level of needs $(n=327)$} \\
\hline & $\bar{x}$ & S.D & Level \\
\hline \multirow[t]{2}{*}{ 9. A research population search function } & 4.61 & 0.48 & Very \\
\hline & & & high \\
\hline 10. A research tools search function & 4.07 & 0.72 & High \\
\hline 11. A statistic used search function & 3.84 & 0.84 & High \\
\hline 12. A research level search function & 4.09 & 0.76 & High \\
\hline \multirow{2}{*}{$\begin{array}{l}\text { 13. A search function showing research statement or } \\
\text { problem }\end{array}$} & 4.60 & 0.49 & Very \\
\hline & & & high \\
\hline $\begin{array}{l}\text { 14. A search function showing research evaluators or } \\
\text { advisors }\end{array}$ & 3.54 & 0.73 & High \\
\hline 15. A search function showing research serial number & 3.78 & 0.68 & High \\
\hline 16. A search function showing researcher's serial number & 3.92 & 0.59 & High \\
\hline 17. A search function showing researcher's contact & 3.87 & 0.69 & High \\
\hline \multirow[t]{2}{*}{ 18. A research area search function } & 4.68 & 0.46 & Very \\
\hline & & & high \\
\hline Average & 4.07 & 0.66 & High \\
\hline
\end{tabular}

According to the data in Table 2, basic research information aspect, it was found that overall needs on system design and development was at a high level $(\bar{X}=4.07, S . D=0.66)$, further, there were 3 highest needs items as a research area search function $(\bar{X}=4.68, S . D=0.46)$, a research population search function $(\bar{X}=4.61, S . D=0.48)$, and a search function on research statement or research problem $(\bar{X}=4.60, S . D=0.49)$ respectively. 
International Journal of Managing Information Technology (IJMIT) Vol. 11, No. 4, November 2019 Table 3. Average, SD, and level of researchers' needs on research for Southern development: related research information

\begin{tabular}{|c|c|c|c|}
\hline \multirow{2}{*}{ Needs items } & \multicolumn{3}{|c|}{ Level of needs $(n=327)$} \\
\hline & $\bar{x}$ & S.D & Level \\
\hline 1. A search function showing researcher's affiliation & 3.87 & 0.79 & High \\
\hline $\begin{array}{l}\text { 2. A function showing research regarding researcher's } \\
\text { expertise }\end{array}$ & 4.20 & 0.65 & High \\
\hline $\begin{array}{l}\text { 3. A search function showing results regarding research } \\
\text { types and designs }\end{array}$ & 4.04 & 0.69 & High \\
\hline 4. A search function showing research data types & 4.14 & 0.62 & High \\
\hline $\begin{array}{l}\text { 5. A search function showing academic fields (science, } \\
\text { technology, and social science) }\end{array}$ & 4.63 & 0.48 & Very high \\
\hline $\begin{array}{l}\text { 6. A search function showing research from the } 12 \\
\text { disciplines of NCRT }\end{array}$ & 4.64 & 0.48 & Very high \\
\hline $\begin{array}{l}\text { 7. A search function showing connections between } \\
\text { research and the Southern province group strategies. }\end{array}$ & 4.54 & 0.49 & Very high \\
\hline $\begin{array}{l}\text { 8. A search function showing research area regarding the } \\
\text { Southern province group }\end{array}$ & 4.74 & 0.43 & Very high \\
\hline $\begin{array}{l}\text { 9. A search function showing research according to } \\
\text { research areas }\end{array}$ & 4.66 & 0.47 & Very high \\
\hline 10. A search function showing research grants & 3.82 & 0.71 & High \\
\hline 11. A search function showing research publication types & 3.98 & 0.68 & High \\
\hline $\begin{array}{l}\text { 12. A search function showing research publication } \\
\text { periods }\end{array}$ & 3.77 & 0.69 & High \\
\hline 13. A search function showing research publishers & 3.72 & 0.71 & High \\
\hline 14. A search function showing research rights or patents & 4.01 & 0.72 & High \\
\hline 15. A keyword search function & 4.60 & 0.59 & Very high \\
\hline $\begin{array}{l}\text { 16. A search function showing population based on } \\
\text { sampling designs }\end{array}$ & 3.86 & 0.82 & High \\
\hline $\begin{array}{l}\text { 17. A search function showing research data collection } \\
\text { resources }\end{array}$ & 3.76 & 0.73 & High \\
\hline $\begin{array}{l}\text { 18. A search function showing research data collection } \\
\text { techniques }\end{array}$ & 3.66 & 0.58 & High \\
\hline $\begin{array}{l}\text { 19. A search function showing research data analysis } \\
\text { techniques }\end{array}$ & 3.76 & 0.65 & High \\
\hline $\begin{array}{l}\text { 20. A search function showing research data collection } \\
\text { types }\end{array}$ & 3.63 & 0.74 & High \\
\hline 21. A search function showing research summary & 4.66 & 0.47 & Very high \\
\hline $\begin{array}{l}\text { 22. A search function showing related research according } \\
\text { to research references }\end{array}$ & 4.73 & 0.44 & Very high \\
\hline Average & 4.15 & 0.61 & High \\
\hline
\end{tabular}

According to the data in Table 3, related research information aspect, it was found that overall needs on system design and development was at a high level $(\bar{X}=4.15, S . D=0.61)$, further, there were 3 highest needs items as a search function showing research area regarding the Southern 
International Journal of Managing Information Technology (IJMIT) Vol. 11, No. 4, November 2019

province group $(\bar{X}=4.74, S . D=0.43)$, a search function showing related research regarding research references $(\bar{X}=4.73, S . D=0.44)$, and a search function showing research related to its area $(\overline{\mathrm{X}}=4.66, \mathrm{~S} . \mathrm{D}=0.47)$ and a search function showing research summary $(\overline{\mathrm{X}}=4.66, \mathrm{~S} . \mathrm{D}=$ $0.47)$ respectively.

(2.) Synthesized result of administrators needs on research for Southern development, summarized by content analysis (In-depth Interview), collected the data from the needs topic and questions form (qualitative).

The findings on focus group interview revealed that administrators would like information which could identify or reconfirm body of knowledge related to the South. The required information was related to research area, research tools, agriculture and tourism fields, Southern province group research. Further, the information should be implemented as guidelines and further studies in the South development (D-BD1, D-GT2, D-AM3).

According to budgeting aspect, it was found that there was no research grants due to the Ministry of Finance's regulations, yet to obtain research grants it must be asked from NRCT or other funding organizations in terms of supporting research projects (D-BD1, D-AM3). Additionally, it was found that the Office of Strategy Management; Southern province group invited organizations and universities to cooperate on planning strategies also offered research grants for province group scheme under a condition on conducting co-research related to tourism (D-GT2). According to inter-view findings on conditions and needs of Southern province group research budgeting, it was found that even the group needed new innovations, there was signs due to limited budgeting and unclear local knowledge. Further, if there was an information system which supports research works or identifies existing knowledge, research budgets, and connections among research, policies, strategies, and problems, it would be very useful on getting research grants or continuing further studies (D-BD1).

The phase 1 and 2 findings are beneficial for reconfirming existing knowledge and integrating knowledge and research in order to enhance the competitive level. Moreover, all findings were applied to be guidelines on conducting phase 3; the research recommendation system for Southern Thailand development.

\subsection{Developing the research recommendation system for Southern Thailand development (Phase 3)}

Phase 1 (3.1) and Phase 2 (3.2) findings had been brought to conduct in phase 3 (3.3) which are (1.) Ontology development base on knowledge engineering to gather basic knowledge structures (2.) system development to construct the system according to the needs and concepts on usercentered design and system approach.

\section{(1.) Ontology development base on knowledge engineering}

(1.1) Underlying concepts: To develop ontology for the system it was designed as a knowledge structure. This development is from 2 domains; research aspects domain referring to knowledge related to the research for development of Southern Thailand and research work domain referring to knowledge related to the scope of the research for development of Southern Thailand into concepts, classes, sub-classes, also systematically categorizing hierarchy of classes and subclasses. Protégé Ontology Editor version 3.5 beta and version 5.5 beta had been used to develop the ontology. 
International Journal of Managing Information Technology (IJMIT) Vol. 11, No. 4, November 2019

(1.2) Ontology development procedure: Protégé Ontology Editor Software had been selected as a tool to transfer and store knowledge in terms of ontology and to effectively support semantic search system in terms of knowledge sharing and reusing. The procedure is as follows;

(1.2.1) Developing ontology; related research knowledge had been analyzed and studied for gathering structures and relationships in detail and getting some as representatives and defining clear scopes of the study and setting the node Is-a relationships; labeling nodes based on the multiple levels of a hierarchy after that considering the relationships which reconfirmed by crosschecking sided and top levels of the instance.

(1.2.2) Considering Role Part-of (p/o) relationships; they should be changeable in terms of property, objection, core, and sibling. And considering Role Attribute-of (a/o); they should be filled or uncountable. Reconfirming every concept; having role physical and object containing Role (Part-of). Defining each concept before relating to others, p/o (Object property) refers to concept on ontology and a/o (Instance) refers to Data on Database or Data type Property and Categorizing semantic group and concept group search.

(1.3) Ontology of the recommender system: The designed ontology had been exported as Ontology Web Language or OWL. The ontology design and development of the recommender system consist of 2 domains, 6 concepts, 55 classes, 303 sub-classes, and 58 properties as a

Figure. 1 


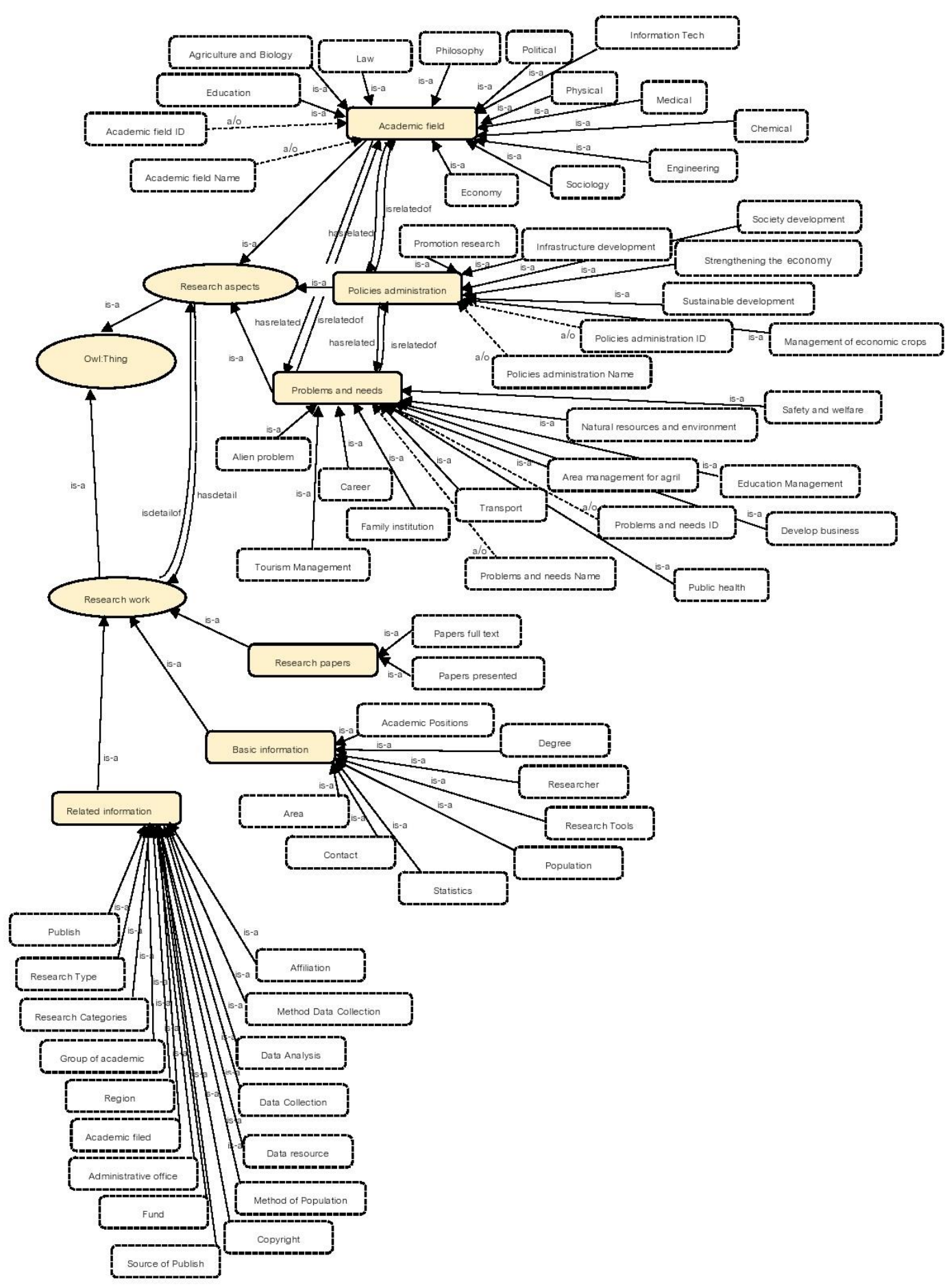

Figure. 1. Southern Development Research Ontology.

(1.4) Ontology evaluation: Ontology evaluation is one of ontology development procedures since it helps tracking the process also reconfirming its reliability, validity, and accuracy. The concepts on scope determining, class, sub-class, concept defining, properties defining, instance 
International Journal of Managing Information Technology (IJMIT) Vol. 11, No. 4, November 2019

defining, application, and future trends on ontology development were used to generate 5-rating scale ontology development evaluation form [32, 33, 34]. The ontology had been evaluated by 5 experts in the following fields; knowledge engineering, computer, and information technology, the findings (in Table. 4). According to ontology evaluation findings, the researchers stated the criteria regarding relationship level and knowledge scope as follows [23].

$$
\begin{array}{lr}
4.51-5.00 \text { is Very high } & 3.51-4.50 \text { is High } \\
2.51-3.50 \text { is Average } & 1.51-2.50 \text { is Low } \\
& 1.00-1.50 \text { is Very low }
\end{array}
$$

\begin{tabular}{|c|c|c|c|}
\hline \multirow{2}{*}{ Evaluation items } & \multicolumn{3}{|c|}{ Level of agreement $(n=5)$} \\
\hline & $\bar{x}$ & S.D & Level \\
\hline 1. Determining Scope & 4.47 & 0.42 & High \\
\hline 2. Defining Classes, Sub-class, Concept & 4.03 & 0.29 & High \\
\hline 3. Defining Properties & 4.15 & 0.25 & High \\
\hline 4. Defining Instance & 4.60 & 0.28 & Very high \\
\hline $\begin{array}{l}\text { 5. Application and future trends on ontology } \\
\text { development }\end{array}$ & 4.20 & 0.28 & High \\
\hline Average & 4.21 & 0.34 & High \\
\hline
\end{tabular}

Table 4. Ontology evaluation findings

According to the data in Table 4, the results were the overall ontology was at a high level $(\overline{\mathrm{X}}=$ 4.21, S.D $=0.34)$, yet there were 4 high level items as Determining Scope $(\bar{X}=4.47$, S.D $=0.42)$, Application and future trends on ontology development $(\overline{\mathrm{X}}=4.20$, S.D $=0.28)$, Defining Properties $(\overline{\mathrm{X}}=4.15$, S.D $=0.25)$, and Defining Classes, Sub-class, Concept $(\overline{\mathrm{X}}=4.03$, S.D $=$ $0.29)$ respectively. There was only 1 highest level as Defining Instance ( $\bar{X}=4.60, S . D=0.28)$.

\section{(2.) Developing the recommendation system}

The system and a part of knowledge base system was developed based on the findings from Phase 1 (3.1), Phase 2 (3.2) and phase 3 (from ontology development base on knowledge engineering step)

\section{(2.1) Underlying theories}

2 theories were adopted to develop the system as (1) System Approach: using a system to manage information as scoping problems or suggesting solutions. (2) User-Centered Design: exploring problems and user's needs and interests [22]. Moreover, phase 2 findings were used to design user interface. The steps on developing are as follows;

Step 1) Designing database: MySql was used to design a server and database and PHP was used to design the system interface.

Step 2 ) Mapping Database to Ontology: To enhance search ability Apache Jena API which is an open source map tool framework for semantic search was used to get information from database and create Resource Description Framework or RDF. Then, SPARQL (SPARQL Protocol and RDF Query Language) was used to search for information through the designed ontology and show search results on the system [29]. 
International Journal of Managing Information Technology (IJMIT) Vol. 11, No. 4, November 2019

Step 3) User Interface: JavaScript, PHP, and CSS were combined to design a beautiful friendlyuser interface.

Role of the recommendation system is to suggesting useful research information to users as analyzing then selecting the information systematically.

\section{(2.2) The system functions}

\section{(2.2.1) Storing aspect; the system could store the following items;}

(1) Research information, (2) Researcher information, (3) Research category, (4) Research abstracts, (5) Research files and pictures, (6) Related research primary and secondary disciplines, (7) Related research primary and secondary policies, (8) Related research primary and secondary problems, (9) Research methodology, (10) Research related to Southern province groups; Southern border, the Thai Gulf coast, and the Andaman coast, (11) Departments and research funding, (12) Research publications and copyrights' owners and (13) Research articles

\section{(2.2.2) Processing aspect}

(1) It is a combined system of relational database and ontology.

(2) To search for information it is convenient to choose primary and secondary requirements as discipline, policy, problems, statistics used, or research area.

(3) Processing data with relational database and ontology leads to effective search and shows semantic search results according to the design ontology.

(4) Systematic processing leads to fast semantic search.

\section{(2.2.3) Functioning aspect}

The recommendation system works as semantic web and the architecture as Figure. 2. 


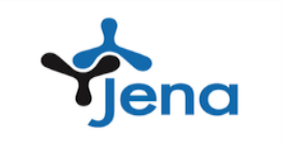

4. Map tool API Semantic Web Framework

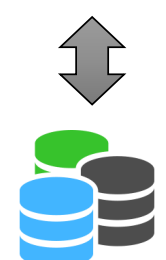

3. Database
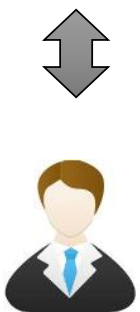

2. Expert / Admin

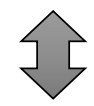

1. Collect data related to the Southern for synthesis

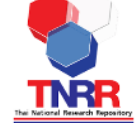

$\begin{gathered}\text { Southern } \\ \text { University } \\ \text { database }\end{gathered}$
Thail IS

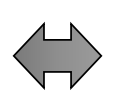

5. Knowledge Base Ontology (OWL)

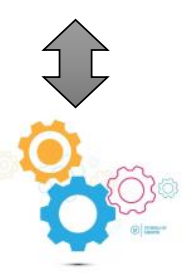

6. Inference Engine

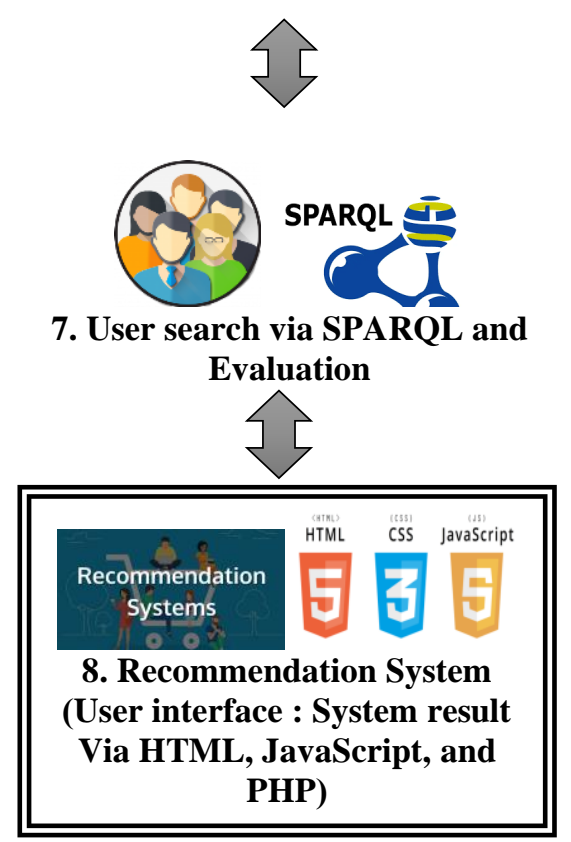

Figure. 2. The recommendation system architecture.

\section{(2.3) The system development procedure}

(2.3.1) Transcribing ontology data into Ontology Web Language or OWL by Protégé Ontology Editor Version 3.5 beta and Version 5.5 beta.

(2.3.2) Creating a database to store all the collected data by using MySql Database. There were 38 tables created according to data relationships and relational database system.

(2.3.3) Mapping Database to Ontology in OWL by using Apache Jena API to draft RDF (Resource Description Framework). Then, SPARQL (SPARQL Protocol and RDF Query Language) was used to search for information through the designed ontology and show accurate results [29]. After connecting the database and ontology further steps were continued as follows (1.) Mapping Class Table (2.) Mapping Property Column; Data type Property and Object Property and (3.) Mapping Vocabulary between words of data in data table to class inside ontology knowledge base. 


\section{(2.4) The system evaluation findings}

The result was the system shows search result according to keyword and/or other conditions. Then, the system recommends related research regarding the keyword and/or conditions and the search results also show relate academic fields, policies, strategies, problems, needs of community, basic information, and relate research information. The system had been developed in accordance with users' needs and it was evaluated and used by 25 experts in various academic fields were asked to evaluate the system regarding (1) information presentation and report (2) user support (3) information search (4) support system (5) overall system and (6) the usefulness of the system. The 5-rating scale on satisfaction survey was delivered to the experts along with the system link. Moreover, the search effectiveness was measured by studying all keyword searches in accuracy, recall, precision, and F-measure to study practical solutions for the system $[32,33,34]$. The system screen in Figure. 3. And according to the system evaluation and trial, the results as Figure. 4.

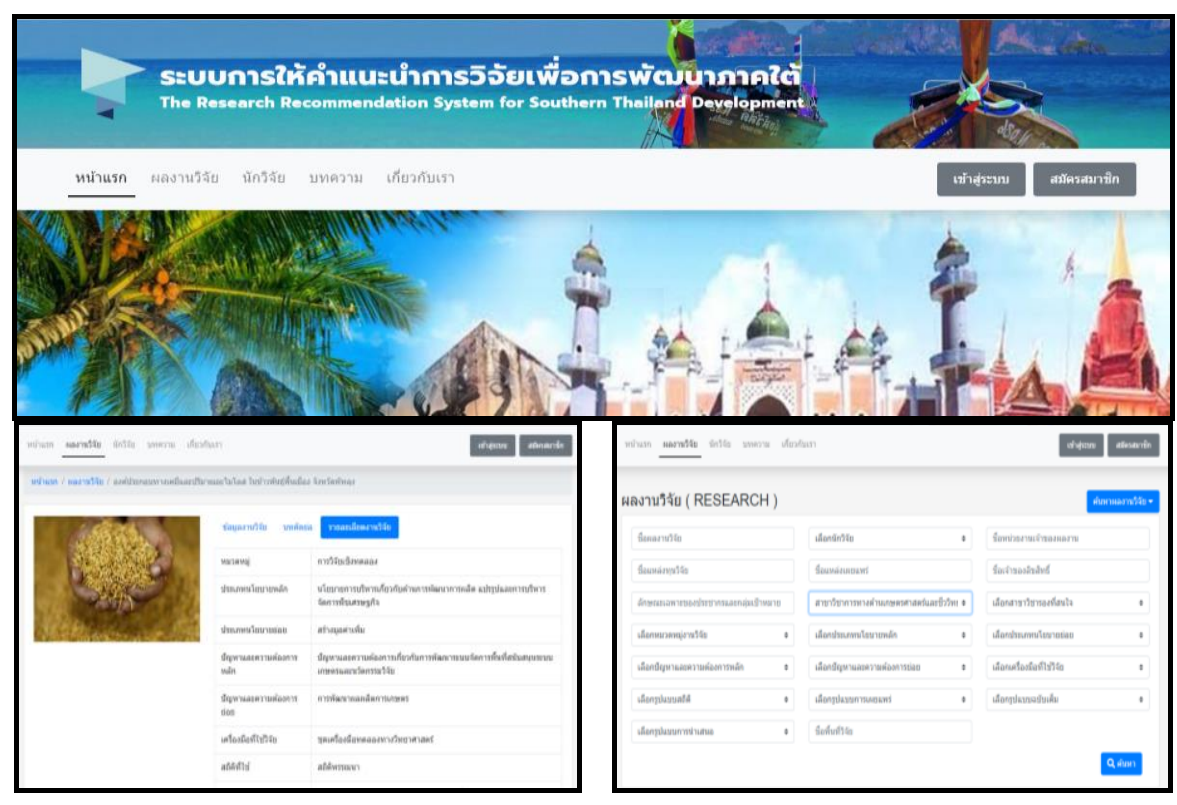

Figure. 3. The system screen.

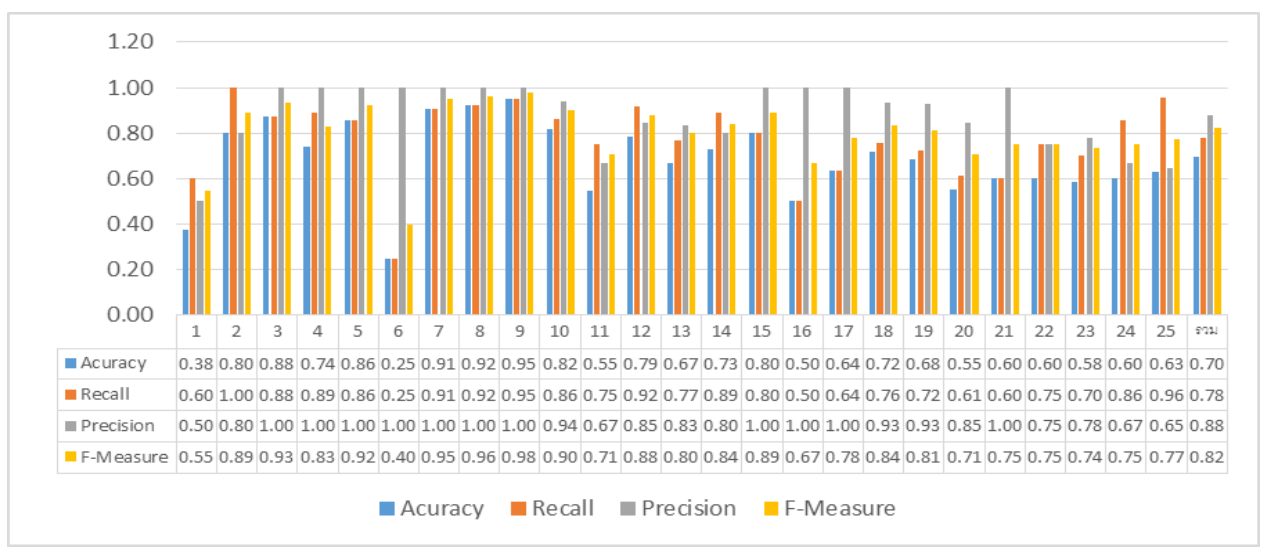

Figure. 4. The results on accuracy, Recall, Precision and F-measure of the system. 
International Journal of Managing Information Technology (IJMIT) Vol. 11, No. 4, November 2019 According to the data in Figure 4, shows the results on Accuracy, Recall, Precision, and Fmeasure of the system. The chart shows that the overall system is at a good level (0.70-0.88); Accuracy is 0.70 , Recall is 0.78 , Precision is 0.88 , and F-measure is 0.82 respectively.

The findings of opinions and satisfaction of the experts and the users, the researchers stated the criteria regarding as follows [23].

$$
\begin{aligned}
& 4.51-5.00 \text { is Very high } \\
& 2.51-3.50 \text { is Average } \\
& 1.00-1.50 \text { is Very low }
\end{aligned}
$$

3.51-4.50 is High

1.51-2.50 is Low

Table 5. Opinions and satisfaction of the experts and the users.

\begin{tabular}{lcll}
\hline \multirow{2}{*}{ Evaluation items } & \multicolumn{3}{c}{ Level of agreement (n=25) } \\
\cline { 2 - 4 } & $\bar{X}$ & S.D & Level \\
\hline 1. Information presentation and report & 4.10 & 0.12 & High \\
\hline 2. User support & 4.07 & 0.17 & High \\
\hline 3. Information search & 4.20 & 0.13 & High \\
\hline 4. Support system & 4.25 & 0.12 & High \\
\hline 5. Overall system & 4.07 & 0.16 & High \\
\hline 6. Usefulness of the system & 4.12 & 0.18 & High \\
\hline \multicolumn{1}{c}{ Average } & $\mathbf{4 . 1 4}$ & $\mathbf{0 . 1 4}$ & High \\
\hline
\end{tabular}

According to Table 5, The user's overall opinions and satisfaction it was found at a high level $(\overline{\mathrm{X}}=4.14, \mathrm{~S} . \mathrm{D}=0.14)$, further, 2 items are at a high level; support system $(\overline{\mathrm{X}}=4.25, \mathrm{~S} . \mathrm{D}=0.12)$ and information search $(\overline{\mathrm{X}}=4.20, \mathrm{~S} . \mathrm{D}=0.13)$ respectively. The least preferred items are user support and overall system $(\overline{\mathrm{X}}=4.07, \mathrm{~S} . \mathrm{D}=0.17)$

\section{RESULTS AND DISCUSSION}

\section{(4.1) Needs analysis on the research recommendation system's design and development}

It was found that 327 users who were researchers, scholars, administrators of 78 organizations shared 2 information needs aspects as basic research information and related research information. These needs were considered as basic data which users are able to collect, refer, summarize, and apply to their further studies as follows:

Needs on basic research information is at a high level since researchers could use this data on stating the problems. Moreover, researchers could make research plans more effective as setting goals, exploring population and research area. The data is crucial for budgeting and time frame [24]. Therefore, it is better if users could gather basic research information in advance.

Related research information is at a high level as same as needs on basic research information. Users need more information, for instance, specific research areas in the South as border, Thai gulf, or Andaman sea, references, or abstracts. Once users could access to secondary or tertiary sources, it is possible for users to conduct more productive research also create research network and community for future development $[25,30,31]$. Besides, gathering references and abstracts is value-added to research [26]. 


\section{(4.2) Scope of knowledge on research for Southern development}

The scope consists of systematic knowledge structure, knowledge sets, categories, concepts and classes related to Southern research, strategies, guidelines, and management policies. The knowledge structure will be applied to use as a framework on setting Southern research or relate research topics, trends, grants, information system development or database, other further studies [11]. It could be used to setting subject, phrase, or keyword in categorizing information $[9,16]$ also the system keywords could be used with other databases or search engines. And the ontology could be further developed as a tool on semantic search system which could relate various aspects [12] and show the result in one search, for example, primary and secondary research topics, disciplines, strategies, problems, and needs. Besides, the system is able to show search results on research methodology, data collection, population and target groups, research area, and research province group area.

\section{(4.3) Research recommender ontology for Southern development}

The ontology was developed according to research knowledge structure for Southern development and it covered all important research knowledge related to the Ninth National Research Policy and Strategy (2017-2021), the Twelfth National Economic and Social Development Plan (2017-2021) and the 20-year National Strategy framework (2017-2036), and 3 departments of administration and strategy planning of Southern province group development framework (2018-2021) [27, 28]. Underlying concepts of the ontology are in hierarchy shown as primary and secondary relationships $[18,19,20]$. Therefore, the structure is new and could be used as follows;

(1) It is reusable by adding classes, for instance, disciplines, strategies, policies, problems, or needs.

(2) It is a prototype of ontology development in region or province level.

\section{(4.4) The research recommender system for Southern development}

The final version of the system is similar to semantic web which stores data, runs by ontology, shows search results as relationship sets of information $[11,12]$ for example, shows research that relate to problems and strategies, research data collection area, population and target groups, or research tools.

The highlight aspect of this research is not only scopes and body of knowledge regarding situations, needs, strategies, and policies of the South which reflect gaps and lead researchers to acquire systematic plans and solutions but also it is able to disseminate on further effective recommender system developments as reducing search procedures, redundancy, and costs.

Additionally, the research findings could be applied in terms of policy area and national strategies, for example, the body of research knowledge on tourism and agricultural development which is crucial for national economic and resource. The government could take the knowledge into account the research or tourism policies, agricultural production as Start-up: Smart Tourism and Smart Agro Technology that supports production capacity and business value of products and services, responds to needs and expectations of customers, enhances competition capacity in nation level, or applies as a part of solutions $[35,36]$.

The researchers plan to improve the system in response to the research limitations. First, diffusion of the model in the future in changing regarding needs, strategies, policies, or plans, the researchers plan to develop the system as applying trend analysis or trend exploration, cyclical 
International Journal of Managing Information Technology (IJMIT) Vol. 11, No. 4, November 2019

pattern analysis and environment survey to analyze and evaluate other factors along with historical information. Then the researchers will spot trend [37] align with various aspects on the South and Thailand. Therefore, the system will be more effective as it will be covering all possible aspects precisely. Moreover, users will be able to gather the most updated, reliable, precise, and valid information to use in their research [38]. Besides, this further development is a value-added and covers development issues in regional and national level. Finally, distribution platforms could be more accessible for users in a form of mobile application, researchers plan to develop the system as a mobile application which is flexible and responsive. Then researchers will test the application and develop additional features as online sharing, wireless printing, and chatbot so that it will be easy to access anywhere and anytime. Further, it could also enhance long-term learning community.

\section{Conclusions}

The findings on identifying needs phase helps researchers to develop the system accurately and flexibly according to the needs and user center design, therefore, the system could be a prototype for students, researchers, administrators, or interested users to access and study the system structure individually. This system was developed from systematic ontology which could distinguish relevant or irrelevant data, therefore, this leads to research effectiveness as decreasing research topic and budgeting redundancy, saving search time, suggesting relevant research information or trends, and enhancing further studies. The knowledge structure inside the system allows us to see relationships among research, policies, strategies, disciplines, and problems and needs of Southern people so that researchers or interested people could use this structure to explore future research trends or use it as a resource for current studies. And the system is practical since it stores research data, saves time, and is easy access.

\section{ACKNOWLEDGEMENTS}

With this research article the researcher would like to thank you the Office of Higher Education Commission (OHEC) on kindly provided research grant to improving the research also thank you the Department of Library and Information Science, Prince of Songkla University that kindly be affiliation and thank you to Department of Information Science, Khon Kaen University for support.

\section{REFERENCES}

[1] Office of Southern Border Administration Management. (2018). Policy and Strategic of Southern Borde report, Songkla, Thailand.

[2] Bureau of Land Survey and Land Use Planning. (2019). Land use Planning and Land use Change Report 2018, Bangkok, Thailand.

[3] Office of the National Economics and Social Development Board. (2019). The National Economics and Social Development Plan strategic report, Bangkok, Thailand.

[4] Kewsuwun, N., Kwiecien, K., Sae-Chan, C. (2019). "The Synthesis of Problem Needs and Strategies of 14 Southern Provinces Group Administrative Offices with Correspondence of Academic Branches from National Research Council”, Parichart Journal, Vol. 32, No. 1, pp. 389-423.

[5] Office of Southern Andaman Administration Management. (2019). Policy and Strategic of Southern Andaman report, Phuket, Thailand.

[6] Podhisita, C. (2019). The science and art of quality research (8th ed.), Bangkok, Institute for Population and Social Research Mahidol University. 
International Journal of Managing Information Technology (IJMIT) Vol. 11, No. 4, November 2019

[7] Chan-o-cha, P. (2018). Southern Development Plan forward, Songkla, Thailand.

[8] Prasitrathasin, S. (2012). Research Method in Social Sciences (15th ed.), Bangkok, Chulalongkorn University Press.

[9] Mueanrit, N. (2013). The Information Architecture for Research Information Storage and Retrieval, Khon Kaen. Ph.D. Dissertation for Doctor of Philosophy in Information Studies. Khon Kaen University.

[10] Chan, L.M. (1985). Cataloging and classification: Intro, New York, McGraw-Hill Book.

[11] Panawong, J. (2015). Development of Knowledge Base System for Northeastern Thailand, Khon Kaen. Ph.D. Dissertation for Doctor of Philosophy in Information Studies. Khon Kaen University.

[12] Archint, N. (2014). Semantic Web Technologies, Khon Kaen, Klangnanawitaya Press.

[13] Boonprasaert, U. (2012). Action Research, Bangkok, Office of the Education Council Press.

[14] Tripathy, B.K., Acharjya, D.P. (2014). Global Trends in Intelligent Computing Research and Development, Hershey, PA of IGI Global.

[15] SKOS. (2018). Knowledge Management Tools an introducing organizational knowledge, http://www.knowledge-management-tools.net/introducing-organizational-knowledge.php (Retrieved 12.07.2018).

[16] Hodge, G. (2000). Systems of knowledge organization of digital libraries: beyond traditional authority files, Washington, Digital Library Federation.

[17] Hjorland, B. (2015). Nine Principles of Knowledge Organization, Copenhagen, DK-2300, The royal school of Library and Information Science.

[18] Taylor, A.G., Joudrey, D.N. (2009). The Organization of Information, Wesport, CT, Libraries Unlimited.

[19] Rowley, J. (1992). Organizing knowledge: intro information retrieval (2nd ed.), London, Hampshire, Ashgate Publishing.

[20] Fricke, M. (2012). Logic and the Organization of Information, New York, Springer.

[21] Kewsuwun, N., Kwiecien, K., Sae-Chan, C. (2018). "Knowledge Structure of research for the Southern of Thailand development", Proceedings of The LISSASPAC: International Conference on Library and Information Science: From Open Library to Open Society 2018, Vol. 1, No. 1, pp. 332345 .

[22] Norman, D. (1996). Administrative Office Management: AOM (11th ed.), Cincinnati Ohio, SouthWestern Education Publishing.

[23] Srisaad, B. (2002). Introduction to basic research (7th ed.), Bangkok, Suweeriyasarn Publishing.

[24] Trumikaborworn, S. (2017). Formulation of integrated research problems in accordance with the research policy, http://www.ubu.ac.th/web/files_up/08f2017060214303240.pdf (Retrieved 16.09.2019).

[25] Areejitranusorn, C. (2006). "Research network for research development", Journal of Medical Technology and Physical Therapy, Vol. 18, No. 2, pp. 43-45.

[26] Wipawin, N. (2016). Digital data management process and research data management standards in digital data warehouses: research information warehouse, Bangkok, Sirindhorn Anthropology Center (Public organization).

[27] National Science and Technology Development Agency. (2017). The 6th Strategic Plan (2017-2021), https://waa.inter.nstda.or.th/stks/pub/2017/20170630-strategy-plan-2560-2564-minimizeeng.pdf (Retrieved 01.10.2019). 
International Journal of Managing Information Technology (IJMIT) Vol. 11, No. 4, November 2019

[28 ]Office of the National Economic and Social Development Board Office of the Prime Minister. (2017). The Twelfth National Economic and Social Development Plan (2017-2021), http://www.nesdb.go.th/nesdb_en/ewt_w3c/ewt_dl_link.php?nid=4345 (Retrieved 01.10.2019).

[29] Anonymous. (2013). SPARQL Protocol and RDF Query Language, https://en.wikipedia.org/wiki/SPARQL\#cite_note-2, (Retrieved 01.10.2019).

[30] Davenport, T., Prusak, L. (1998). Working Knowledge, USA, Harvard Business School Press.

[31] Houda, S., Naila, A., Samir, B. (2019). "Knowledge Management and Reuse in Virtual Learning Communities, International", Journal of Emerging Technologies in Learning, Vol.14, No. 16, pp. 2338.

[32] Denny, V. (2010). Ontology Evaluation, Germany, Karlsruhe Institute of Technology.

[33] Pacharawongsakda, E. (2014). Data analysis using basic data preparation techniques, Bangkok, Asia Digital Publishing.

[34] Eric, G., G, Cyril. (2005). "Relation between PLSA and NMF and implications", SIGIR '05: Proceedings of the 28th annual international ACM SIGIR conference on Research and development in information retrieval, Vol. 1, No. 1, pp. 601-602.

[35] Elshimaa Badr E. H, Maria Emmalyn A. De V. C., Salah Hassan M.A. (2019). "IT Service Management System for Central Bank of Sudan", International Journal of Managing Information Technology (IJMIT), Vol.11, No.2, pp. 1-8.

[36] Obaidat, H., Otair, M. A. (2018). "The Impact of Knowledge Management on the Function of Employee Performance Appraisals in Industrial Companies-Case Study", International Journal of Managing Information Technology (IJMIT), Vol.10, No.4, pp. 35-52.

[37] Helmer, O. (1983). Looking forward: A guide to future research. Beverky Hills, CA: Sage.

[38] Ralph, M. Stair, George, W. Reynolds. (2001). Fundamentals of Information Systems. Boston press, Boston.

\section{AUTHORS}

Nawapon Kewsuwun is a Ph.D. Candidate in Information Studies at Khon Kaen University (KKU) (Got the grant as the project "The Development of lecturer and Personnel for Higher Education Institutions in the Specialized Development Zone of the Southern Border Provinces" from Ministry of Higher Education, Science, Research and Innovation, Thailand.). He got the bachelor degree: bachelor of business admiration in Computer Information System, the master degree: master of Industrial Education in Educational Technology, (tn.kewsuwun@hotmail.com).

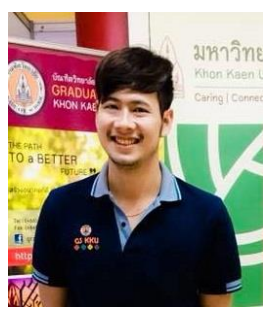

Kanyarat Kwiecien is an assistant professor at department of Information Sciences, Khon Kaen University (KKU), Thailand. She got the bachelor degree: Bachelor of art in Library Sciences and Information Sciences, the master degree: master of art in Library and Information Sciences and got the Ph.D. in Information and Communication Technology for Education from Chulalongkorn University, Thailand. She has experience in many positions such as the director at Digital Humanities Research Group, an assistant director of KKU - Smart Learning, and an editorial board of Journal of Information Sciences Khon Kaen

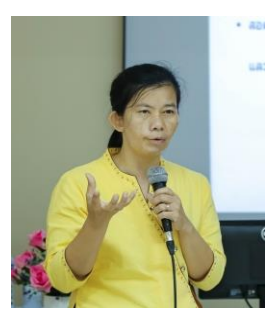
University. 
International Journal of Managing Information Technology (IJMIT) Vol. 11, No. 4, November 2019

Chumchit Sae-Chan is an assistant professor at department of Library and Information Sciences, Prince of Songkla University (PSU), Thailand. She got the bachelor degree: Bachelor of Education in Education, the master degree: master of art in Library Sciences and got the Ph.D. in Library Sciences from Simmons College, U.S.A. She has experience in many positions such as the deputy dean for Research and Graduate Studies at Prince of Songkla University (PSU), an editorial board in Journal about knowledge and Information management, library and information sciences and related filed, and an expert of National Research Council

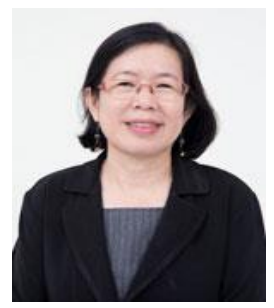
of Thailand (NRCT). 